\title{
FACTORS AFFECTING THE DETERIORATION OF WATER MAIN
}

Mohamed I. Amer, Ahmed H. Ibrahim, Mohamed S. Yamany

\begin{abstract}
The civil infrastructure including buildings, highways, bridges, and water/sewer systems, is crucial for ecor and prosperity. As water mains deteriorate structurally and functionally, their breakage rates increase, net' hydraulic capacity decreases, and the water quality in the distribution system may decline. So there are th one affects the condition of water mains themselves, and the other influences negatively general health of things especially human beings. To confront these threats, it is necessary to rate the conditions of existing by whether direct inspection or using one of the developed condition rating models. That's to make a decis replacement, maintenance, or no action. Nevertheless typical water distribution systems comprise not onl) but also more than thousands of underground buried pipes, direct inspections for all of them are often ext। expensive. Therefore, for more efficiency and less cost, it is supposed using one of the condition rating mc paper is presented to identify the factors affecting the condition of water mains which will be considered tr categorizing the conditions of water mains. The aim of this research is to identify the factors affecting the of water mains and to rank them according to their importance indexes. In this research, three categories environmental and operational factors are supposed. A designed convenient questionnaire is sent to severi various attitudes; construction companies, consultant offices, management companies, and owners to eva diverse factors. Eventually, a robust analysis for all available and trusted data shows that there are eight $f_{i}$ are the most effective factors on water mains deterioration. These factors are: pipe type, age, diameter, si type, backfill soil type, operational pressure, and breakage rate
\end{abstract}

